\title{
Educação Matemática e suas relações com campos disciplinares e profissionais na elaboração de novos saberes
}

\author{
Wagner Rodrigues Valente
}

\begin{abstract}
Resumo: 0 texto apresenta resultados de pesquisa que vêm sendo obtidos por projeto de investigação coletiva que toma por tema a matemática presente no ensino e na formação de professores. Essa pesquisa de caráter histórico-epistemológico utiliza-se de ferramental teórico-metodológico vindo da sociologia (Pierre Bourdieu), da história social da educação (Rita Hofstetter e Bernard Schneuwly e, também da história cultural (André Chervel). $\mathrm{O}$ artigo norteia-se pela questão: que processos e dinâmicas estão presentes nas mudanças que ocorrem relativamente à matemática considerada como um saber profissional do professor que ensina matemática? Este estudo tem por objetivo demonstrar que tal questão se revela como própria e original à Educação Matemática, descortinando as relações que esse novo campo de pesquisa estabelece com o campo disciplinar matemático, as ciências da educação e o campo profissional da docência.
\end{abstract}

Palavras-chave: Educação Matemática. Campo científico. Saber profissional.

Wagner Rodrigues Valente Professor Associado Livre Docente do Departamento de Educação da UNIFESP, Brasil.

Dittp://orcid.org/0000-0002-2477-6677 $\triangle$ wagner.valente@unifesp.br

Recebido em 15/04/2021 Aceito em 06/05/2021

Publicado em 26/07/2021

\section{Mathematical Education and its relations with disciplinary and professional fields in the development of new knowledge}

Abstract: The text presents research results that have been obtained by a collective research project that takes as its theme the mathematics present in teaching and teacher training. This historical-epistemological research uses theoretical-methodological tools from sociology (Pierre Bourdieu), social history of education (Rita Hofstetter and Bernard Schneuwly, and also cultural history (André Chervel). The article is guided by the question: what processes and dynamics are present in the changes that occur in relation to mathematics considered as a professional knowledge of the teacher who teaches mathematics? This study aims to demonstrate that this question appears to be unique and original to Mathematics Education, revealing the relationships that this new field of research establishes with the mathematical disciplinary field, the educational sciences and the professional field of teaching.

Keywords: Mathematical Education. Scientific field. Professional knowledge.

\section{La Educación Matemática y sus relaciones con los campos disciplinarios y profesionales en el desarrollo de nuevos conocimientos}

\begin{abstract}
Resumen: El texto presenta resultados de investigación que han sido obtenidos por un proyecto de investigación colectiva que toma como tema las matemáticas presentes en la docencia y la formación docente. Esta investigación histórico-epistemológica utiliza herramientas teórico-metodológicas de la sociología (Pierre Bourdieu), la historia social de la educación (Rita Hofstetter y Bernard Schneuwly, y también la historia cultural (André Chervel). El artículo se guía por la siguiente pregunta: ¿qué procesos y dinámicas están presentes en los cambios que ocurren en relación a la matemática considerada como un conocimiento profesional del docente de las matemáticas? Este estudio tiene como objetivo demostrar que esta pregunta aparece como única y original para la Educación Matemática, revelando las relaciones que este nuevo campo de investigación establece con el campo disciplinar matemático, las ciencias de la educación y el campo profesional de la docencia.
\end{abstract}

Palabras clave: Educación Matemática. Campo científico. Conocimientos profesionales. 


\section{Considerações iniciais}

A caracterização de um campo disciplinar, dentre outros elementos, aponta para a originalidade de suas problemáticas de pesquisa relativamente aos demais campos já estabelecidos e consolidados. A emergência de um novo campo precisa explicitar em que medida as interrogações que formula já não foram respondidas por outros campos. A Educação Matemática como campo de pesquisa vem buscando, para se consolidar, elaborar questões próprias, originais, e, nesse sentido, necessita afastar-se dos campos disciplinares da Matemática e das Ciências da Educação. Apregoar-se como área interdisciplinar constitui artifício retórico da Educação Matemática que visa, dentre outras coisas, atenuar tensões que sempre estão presentes entre campos disciplinares diferentes, que lutam pela hegemonia da autoridade científica sobre um dado tema. Em específico, no caso da Educação Matemática, o tema que parece estar sempre em debate envolve o ensino e a formação de professores (FIORENTINI et al., 2016, 2017). Tal assunto é trazido a este texto tendo em vista um dos aspectos desse tema. $E$ ele nos parece fundamental: os saberes envolvidos na formação de professores e no ensino de matemática.

Desse modo, o presente artigo toma por referência resultados de pesquisa que vêm sendo obtidos com o desenvolvimento de projeto coletivo amplo, que aborda a temática do saber profissional do professor que ensina matemática. Interroga-se: que processos e dinâmicas estão presentes nas mudanças que ocorrem relativamente à matemática considerada como um saber profissional do professor que ensina matemática? Este estudo tem por objetivo explicitar que tal problemática revela-se original, podendo ser incluída como uma das interrogações próprias da Educação Matemática.

\section{Campo disciplinar}

No ano letivo francês de 2000-2001, Pierre Bourdieu ministrou, no Collège de France, um curso que ganhou sistematização em obra publicada em 2001 intitulada "Science de la Science et réflexitivité"1. Logo às páginas iniciais, o autor explicita o objetivo de seu livro: fazer a ciência, a produção científica, passar por uma análise histórico-sociológica com a intenção de permitir aos cientistas melhor compreender os mecanismos sociais que orientam as práticas científicas

\footnotetext{
${ }^{1}$ A obra, posteriormente, ganhou tradução para o espanhol, em 2003, sob título "El ofício de científico" (Editorial Anagrama, Barcelona). No ano seguinte, em 2004, o texto foi traduzido para o português, sob título "Para uma sociologia da ciência" (Edições 70, Lisboa).
} 
(BOURDIEU, 2001). Na obra, Bourdieu retoma sua formulação teórica, elaborada em 1975, relativamente ao conceito de campo, campo científico: "[...] o campo científico, como outros campos, é um campo de forças dotado de uma estrutura, e também um campo de lutas para conservar ou transformar esse campo de forças" (2001, p. 69).

Sem pretender analisar exaustivamente os escritos de Bourdieu consideramos que 0 conceito de campo se presta como ferramenta importante para caracterização de espaços que dialogam com a Educação Matemática, ela mesma um campo científico em vias de consolidação. Assim, com o uso do conceito de campo, é possível tratar do campo disciplinar matemático, ao invés de tratar da matemática, de modo amplo, genérico; também o campo disciplinar das ciências da educação, deixando de mencionar por redução, apenas a pedagogia e os métodos de ensino por si mesmos. É possível, também, avaliamos, alargar o uso do conceito para o que se pode chamar de campos profissionais, como por exemplo, o campo profissional da docência. Também nesse espaço tem-se "um campo de forças dotado de uma estrutura, e também um campo de lutas para conservar ou transformar esse campo de forças" (BOURDIEU, 2001, p. 69)

Para além de caracterização de diferentes searas disciplinares e profissionais, o conceito de campo permite que possam ser discutidos, por determinados parâmetros, os processos e dinâmicas produção de saberes ligados ao ensino e à formação de professores. Em que medida promover o estudo das mudanças ao longo do tempo do saber profissional do professor que ensina matemática nos conduz a uma problemática própria à Educação Matemática? Será ela uma problemática não formulada pelo campo disciplinar matemático e também não inscrita nos problemas das ciências da educação?

\section{Campo disciplinar matemático e ensino}

Todo campo disciplinar tem, dentre os elementos que o constituem, a perspectiva do ensino e da formação de professores. Não importa qual seja esse campo. Física, Linguística, Química, História para se consolidarem como campos disciplinares, precisam importar-se com 0 ensino e com a formação de professores. E neste ponto, vale à pena uma precisão que tomaremos dos estudos de Hofstetter e Schneuwly (2017), que ao mencionarem a expressão "campo disciplinar", buscando indicar o que eles abarcam, indicam que a expressão envolve domínios no seio dos quais convivem, na verdade, diferentes disciplinas diferentes:

A medicina contém em seu seio disciplinas que lhe são próprias como a fisiologia ou a anatomia, e outras que são a ela estrangeiras em parte, e que são transformadas 
por sua integração a seus domínios, como a biologia imunológica ou a sociologia das doenças. (p. 22-23).

Assim, um campo disciplinar reúne uma constelação de disciplinas. Do mesmo modo que os autores mencionam a medicina poder-se-ia enumerar as várias disciplinas contidas no campo disciplinar matemático. Mas, o exemplo dado nos parece suficiente.

A constituição e consolidação de um campo disciplinar para além da necessidade de uma base institucional que possa permitir a profissionalização da pesquisa; do estabelecimento de redes de comunicação de modo a que seja possível a existência de uma comunidade de cientistas visando o trabalho sobre mesmas problemáticas; da produção e renovação de conhecimentos que respondem aos critérios de legitimidade científica, todas essas dimensões presentes no estabelecimento de um campo disciplinar

permitem uma socialização do campo e ela ocorre tanto mais facilmente quanto a disciplina se implanta como uma unidade de estreito imbricamento de ensino e pesquisa. Este desafio formativo está relacionado com aquele da capacidade de uma disciplina de determinar ela mesma os critérios de legitimidade de sua reprodução e de formar seus representantes. (HOFSTETTER; SCHNEUWLY, 2017, p. 23).

Em outras palavras, todo campo disciplinar necessita para garantir a sua própria existência importar-se com o ensino e com a formação de professores. Assim, não deveria, de modo algum, causar estranhamento algo ocorrido, já há muito mais de um século, que tocou às preocupações dos matemáticos com o ensino e a formação de professores. O matemático Félix Klein (18491925) impulsionou a criação da Comissão Internacional de Instrução Matemática². Klein, na Introdução do Volume 1 de sua obra clássica "Matemática elementar de um ponto de vista superior", pregou a necessidade de existir um movimento do ensino universitário de matemática que pudesse atender "as necessidades dos professores das escolas" (KLEIN, 2019 [1908], p. 1). O próprio título de sua obra indica como deveriam relacionar-se a matemática da formação de professores e a matemática das escolas: a matemática elementar tendo em vista a matemática avançada. Para Klein, a matemática superior e a matemática das escolas deveriam constituir um todo orgânico, do elementar ao mais desenvolvido conhecimento matemático. A matemática do ensino superior, a matemática presente na formação de professores, deveria constituir a forma avançada da matemática vista no ensino escolar. Junto à necessidade de um movimento do

\footnotetext{
2 Em 1908, em Roma, matemáticos mostraram-se interessados em discutir, em congresso internacional de matemática, questões ligadas ao ensino. Para tanto, foi criada uma comissão internacional para estudo do ensino de matemática. Constituída a comissão (IMUK - Internationale Mathematische Unterrichtskommission/CIEM Commission Internationale de l'Enseignement Mathématique) foi eleito um comitê central liderado pelo matemático Félix Klein (CIEM, 1908, p. 446). A Comissão, a partir de 1952, passa a ser conhecida como ICMI - International Commission on Mathematical Instruction.
} 
ensino universitário, de modo a atender as necessidades das escolas, também elas, segundo Klein, deveriam incorporar, a todo tempo, formas elementares dos avanços da matemática do ensino superior. A relação, portanto, entre a matemática do ensino superior e a matemática do ensino escolar deveria ser dada, no entender dos matemáticos sob a liderança de Klein, por uma propedêutica. No ensino das escolas estaria a forma elementar da matemática superior do ensino universitário. Desse modo, não haveria defasagem entre a matemática da formação de professores e a matemática que deveria estar presente no ensino escolar.

O paradigma estabelecido por Klein alimenta as ações do campo disciplinar matemático até os dias atuais, tendo em vista as diretivas para o ensino de matemática e formação de professores. Entre nós, e em todos os países de língua portuguesa, divulga-se o Klein Project, por meio do sítio http://klein.sbm.org.br. Para além dessas e de muitas outras ações do campo disciplinar matemático e seu interesse no ensino e na formação de professores, a divulgação a público maior também utiliza Klein como referência. Apenas como ilustração é possível citar os artigos recentes em matérias jornalísticas do matemático Marcelo Viana, do IMPA - Instituto de Matemática Pura e Aplicada. A todo tempo, para caracterizar problemas, atrasos do ensino e toda a sorte de denúncias sobre os assuntos da matemática na escola, Viana traz o saudosismo das ações de Klein... ${ }^{3}$

Assim, a análise dos interesses de um campo disciplinar relativamente ao ensino e à formação de professores não deve ser vista exclusivamente como uma preocupação solidária desse campo com a educação, com os rumos do país em termos amplos. Na verdade, em boa medida, trata-se de assegurar a solidez de um dos pilares em que se afirma a supremacia de uma dada disciplina, de um campo disciplinar. Em nosso caso, do campo disciplinar matemático. Absolutamente não se trata de algo à parte às atividades dos matemáticos desse campo interessarem-se pelo ensino e pela formação de professores. 0 tema constitui-se em elemento integrante e fundamental da própria existência do campo 4 .

\footnotetext{
3 Leiam-se, por exemplo, os artigos intitulados "Nossas escolas ensinam matemática do século 19" " "Que matemática ensinaremos e como?", ambos publicados pelo jornal Folha de São Paulo, dos dias 22 dez. de 2020 e 12 jan. de 2021, respectivamente.

${ }_{4}$ É recorrente na mídia manchetes sobre a falta de professores, sobretudo em disciplinas como Física, Química, dentre outras. Os representantes dos campos disciplinares são sempre chamados a opinar demonstrando enorme preocupação. A leitura dessas preocupações, como se disse, deverá incluir o componente ligado à própria sobrevivência do campo disciplinar. Sem professores, como poderá o campo disciplinar promover a sua socialização e formar os seus representantes?
} 


\title{
4 Ciências da educação e Ensino
}

Sem pretender descortinar uma genealogia do estabelecimento do campo das ciências da educação no Brasil, algo de enorme complexidade e extensão, caberia, para os objetivos deste texto, tão somente, neste item, situar esse campo disciplinar múltiplo em sua relação com a Educação Matemática.

Ao que tudo indica, a partir da segunda metade do século XX, com a criação de cursos de pós-graduação, estabelecem-se tensões entre as ciências da educação e os pesquisadores que se dedicam ao ensino de matemática. Mais precisamente, tais tensões se revelam nos poucos meios de divulgação dos trabalhos daqueles pesquisadores. Mostrava-se exíguo o espaço para publicação de artigos escritos por professores com formação matemática, dedicados ao ensino, buscando refletir sobre questões de práticas profissionais docentes dessa disciplina. Os meios de publicação desses textos estavam tomados pelo campo da Educação. Na avaliação desses trabalhos mais importavam as discussões de caráter amplo educativo, do que os estudos mais pontuais, centrados no ensino e aprendizagem da matemática. À medida em que se avolumavam os estudos e pesquisas voltados à matemática surgia o imperativo de constituição de especialistas para julgamento desses trabalhos. Havia necessidade de serem instituídas autoridades para julgar essa produção que, ao mesmo tempo, tivessem uma expertise em matemática e, além disso, proximidade com a Educação. Sobre essa tensão, no âmbito mesmo da produção acadêmica, Ramos \& Silva (2014) assim ponderaram:

\begin{abstract}
A área de Educação tem forte presença de pesquisadores vindos de cursos de Pedagogia e demais licenciaturas, preocupados com a Educação em geral. Na área de Ensino de Ciências e Matemática, os pesquisadores são advindos de suas áreas de formação, tais como a Física, a Química e Biologia, mas se ocupam não com Educação em geral e sim com a expertise de ensino em suas próprias áreas. Dessa forma, a área se volta para didáticas e metodologias de ensino da própria área e não de temas gerais. Assim, esse grupo procura se constituir como comunidade científica, a partir de uma preocupação sobre as suas próprias áreas e não de temas gerais. A ruptura com o grupo anterior está na busca de uma especificidade que não é própria da área da Educação, e, à medida que se perde essa especificidade, ocorre um movimento de tensão na área (p. 366)
\end{abstract}

$O$ resultado desse processo é conhecido: a separação entre a Educação e o Ensino como áreas de pesquisa. $E$, desse modo, os estudos e pesquisas realizados sob a égide da área de Ensino firmaram-se como trabalhos que envolvem preocupações didáticas, didáticas específicas.

Para o que interessa a este texto, analisar as mudanças nas relações entre campos disciplinares e profissionais, no que toca à matemática, às ciências da educação e ao campo profissional da docência, tem-se uma trajetória seguida pelas didáticas específicas (matemática). 
Elas tomam para si os desafios que um dado campo disciplinar (matemático) tem para estar presente nos ensinos escolares e na formação de professores. As respostas a tais desafios evoluíram ao longo do tempo de modo a que, por exemplo na França, buscou-se criar condições para a emergência do campo científico "Didática da Matemática". Entre nós, trabalha-se na consolidação de um campo sob designação de "Educação Matemática". De outra parte, a existência de diferentes expressões não retira a finalidade comum: busca-se ultrapassar os desafios de trazer o campo disciplinar matemático para a educação básica: uma tarefa didática. $\mathrm{A}$ resposta a tais desafios vem sendo dada pelas chamadas "tendências da Educação Matemática". Dessa maneira, estudos sobre "modelagem matemática", "resolução de problemas", "História da Matemática no ensino", "tecnologias e ensino de matemática" dentre vários outros intentam elaborar processos didáticos de modo a fazer com que o campo disciplinar matemático possa ser matéria de ensino e de aprendizagem de crianças e adolescentes, bem como esteja presente na formação de professores. O questionamento sempre presente para as diversas modalidades de propostas para o ensino de matemática é de caráter didático. Desse modo, preserva-se o campo disciplinar matemático e questiona-se como ele poderá ser ensinado e aprendido pelos estudantes.

A perspectiva do "ensino de matemática" ganha variações. É algo diferente a trajetória seguida pelas didáticas específicas (matemática) e as preocupações com o ensino e formação de professores vindas diretamente do campo disciplinar matemático. No primeiro caso, intenta-se consolidar um novo campo, a Educação Matemática; no segundo, reafirmar um campo existente: o campo disciplinar matemático. Essa reafirmação do campo disciplinar matemático no ensino e na formação de professores, debatendo-se com a Educação Matemática, se dá pela estratégia de não reconhecimento do campo emergente como campo científico:

Penso que a educação pedagógica para futuros professores de Matemática poderia resumir-se a um certo número de preceitos básicos, e que não merece toda a importância e a dimensão que lhe atribuem. [...] Acontece que um certo número de pensadores e de intelectuais dedicados a esta área da educação querem, sobretudo em França e Inglaterra, e em alguns lugares dos Estados Unidos, atribuir à educação matemática a posição e a qualidade da investigação cientifica. Para isso, criam teorias, fazem propostas, oferecem doutoramentos. Tudo isso é muito prejudicial. (LIMA, 2004, p. 141). 
A citação acima foi retirada de entrevista do matemático brasileiro Elon Lages Lima concedida a Nuno Crato, matemático, que em tempo posterior assumiu a pasta de Ministro da Educação de Portugal ${ }^{5}$.

Por certo os processos mencionados acima não são lineares. Há muitas idas e vindas, além de sobreposições. Sabe-se que a Educação Matemática teve peso relativo muito grande na constituição da nova área. Alojada no Ensino, institucionaliza sua autonomia em relação às ciências da educação; de outra parte, depara-se também com a necessidade de embater-se com o campo disciplinar matemático, este zeloso da importância de ter sob seus domínios a autoridade científica para sua socialização e formação de seus futuros representantes. Em algumas universidades brasileiras tais tensionamentos originam cisões nos departamentos de matemática. Criam-se os departamentos de educação matemática.

\section{Produção de novos saberes: cultura escolar, campo, ensino e formação de professores}

Desde, pelo menos, a década de 1980, por meio dos estudos de André Chervel sobre história das disciplinas escolares estabeleceu-se um vigoroso questionamento dos campos disciplinares relativamente aos saberes envolvidos no ensino e na formação de professores. Chervel utilizou como dados empíricos os estudos relativos à gramática francesa e por meio deles mostrou que o papel da escola não se limita a reproduzir saberes elaborados em outras searas. Entenda-se: saberes elaborados pelos campos disciplinares. A gramática escolar pouco ou quase nada tem a ver, na pesquisa histórica realizada por Chervel, com aquela do campo disciplinar da linguística. Assim, a tese central desse pesquisador é a de que, ao longo do tempo, o meio escolar elabora saberes de referência para o ensino.

Estima-se ordinariamente, de fato, que os conteúdos de ensino são impostos como
tais à escola pela sociedade que a rodeia e pela cultura na qual ela se banha. Na
opinião comum, a escola ensina as ciências, as quais fizeram suas comprovações em
outro local. Ela ensina a gramática por que a gramática, criação secular dos linguistas,
expressa a verdade da língua; ela ensina as ciências exatas, como a matemática, e,
quando ela se envolve com a matemática moderna é, pensa-se, por que acaba de
ocorrer uma revolução na ciência matemática; ela ensina a história dos historiadores
[...] (CHERVEL, 1990, p. 180).

Dominique Julia alargou o sentido um tanto restrito dado por Chervel à produção de novos saberes. Julia (2001) fez a defesa da existência de uma cultura escolar, que se constitui a partir

\footnotetext{
50 texto foi publicado originalmente no jornal português Expresso, em 2001, posteriormente publicado no livro "Matemática e Ensino" (LIMA, 2004).
} 
de suas relações conflituosas ou pacíficas que ela mantém com outras culturas. Três eixos são destacados pelo autor como adequados para a análise da cultura escolar como objeto de pesquisa: as normas e finalidades que regem a escola, o papel desempenhado pela profissionalização do trabalho do educador, e a análise dos conteúdos ensinados e das práticas escolares. Assume-se, a partir do estudo desse historiador, que formação de professores mantém relações com o ensino que, dentre outros elementos, produzem saberes.

Nessa perspectiva é possível pensar em produções constituídas pela própria escola, na escola e para a escola a partir das relações conflituosas e/ou pacíficas com outras culturas (JULIA, 2001), com a pedagogia como uma das ciências de referência (CHERVEL, 1990), com práticas sociais e profissionais (HÉBRARD, 1990) e resultado de processos de objetivação e codificação (VINCENT, LAHIRE, THIN, 2001). E tais produções referem-se tanto ao ensino como à formação de professores. Além disso, consideramos ser possível o tratamento que envolve culturas, cultura escolar, espaços de produção própria de significados, como campos, no mesmo sentido atribuído por Bourdieu: sistema de relações objetivas entre posições que ocupam atores de uma esfera e lugar de disputas pelo monopólio da autoridade científica internamente e entre diferentes espaços. A cultura escolar, envolvendo o ensino e a formação de professores constitui-se como espaço descontínuo, campo de produção de saberes para seu próprio consumo em diálogos e embates com outros espaços/culturas que envolvem dentre outras searas, os campos disciplinares.

No Brasil, desde a década de 1990, pelo menos, muitos estudos têm sido desenvolvidos sob a perspectiva iniciada por Chervel e Julia. $E$ tais estudos reafirmam que os saberes presentes no ensino e na formação de professores não são elaborados por meio de lubrificantes como a pedagogia, a didática, aplicadas aos campos disciplinares, para usar a própria terminologia de Chervel (1990).

Em termos mais amplos e mais atuais, um inventário extenso, internacional, sobre as pesquisas que analisam a elaboração de saberes de referência para o ensino e para a formação de professores, tendo em vista essas bases iniciais dadas por Chervel e Julia, foi elaborado por Rita Hofstetter \& Bernard Schneuwly (2020). Para tais pesquisadores, as dinâmicas e processos de produção de novos saberes envolvem, em cada tempo, uma complexa relação entre diferentes campos científicos e profissionais. Tais relações, em boa medida tensas, resultam na produção de referências para o ensino e para a formação de professores. 


\section{A matemática do ensino}

Mesmo sem declarar de modo explícito filiação a uma dada e precisa perspectiva teóricoepistemológica, muitos estudos admitem as diferenças existentes entre os saberes presentes no meio escolar - na cultura escolar, dizendo de modo mais preciso - ou mesmo no campo da docência, e aqueles do meio universitário. A análise mais aprofundada dos argumentos que sustentam essa diferenciação poderá revelar a filiação não explicitada.

As diferenças evocadas entre a matemática da cultura escolar e aquela universitária podem ser vistas tão somente como de grau: os saberes escolares são elementos iniciais da matemática do campo disciplinar, algo próximo da visão de Klein. Ou ainda, os saberes escolares são transposições didáticas dos saberes dos campos disciplinares científicos: a matemática presente na cultura escolar representa uma transposição didática da matemática universitária. Boa parte desses trabalhos utilizam a terminologia "matemática escolar" para designar o saber presente no ensino, distinguindo-a da "matemática acadêmica". Neste segundo caso, a matemática do campo disciplinar matemático. Tais estudos preocupam-se com a distinção entre a matemática presente na escola básica e aquela integrante dos cursos superiores. De fato, a distinção, muitas vezes, liga-se a destacar a diferença existente entre a matemática dos matemáticos e aquela dos professores de matemática. Estabelece-se algo como uma dicotomia: uma matemática superior e uma matemática elementar. $E$, ao que parece, pouco avanço consegue-se na elaboração teórica de respostas à questão relativa à matemática a estar presente na formação de professores. A distinção da matemática escolar relativamente à acadêmica, tudo indica, aprofunda ainda mais a separação entre formação de professores e práticas profissionais da docência.

De nosso ponto de vista, considerar tão somente a "matemática escolar" é algo restritivo, e não abarca os processos e dinâmicas do saber próprio à docência e ao ensino. Retornamos assim às referências anteriores que indicam a criatividade do ensino e da formação na produção de saberes para seu próprio consumo. E, nesse caso, vemos a chance de promover uma ruptura com a dicotomia matemática escolar/matemática acadêmica, de modo diverso daquele formulado por Félix Klein...

Consideramos ser fundamental o estudo das relações mantidas ao longo do tempo entre a formação de professores e a docência propriamente dita. Do nosso ponto de vista, ao estudar historicamente as relações entre a matemática da formação dos professores e aquela matemática presente no ensino ganha-se a possibilidade de analisar processos e dinâmicas de construção e transformação do saber profissional do professor que ensina matemática. Em sentido mais amplo, 
isso significa analisar as relações estabelecidas num dado tempo entre, principalmente, o campo disciplinar matemático, o campo disciplinar das ciências da educação e o campo profissional da docência em matemática. E se nos ativermos a tempos mais recentes, pós-década de 1980 , também deverão estar presentes na análise as relações que envolvem o campo da Educação Matemática.

Na perspectiva do estudo das relações entre diferentes campos científicos e disciplinares, bem como aquele relativo à prática da docência, temos utilizado a análise de matemáticas de naturezas diversas, porém, articuladas. Tal percurso para a pesquisa nos tem levado à investigação das relações estabelecidas entre a matemática a ensinar e a matemática para ensinar, conforme pontuam Bertini et al. (2017).

Desse modo, trabalhamos com o conceito de matemática a ensinar tendo em vista que ele expressa o objeto do trabalho docente, o que o professor precisa ensinar. Além disso, analisamos as relações mantidas entre essa matemática e aquela à qual o professor foi formado, tendo em vista um saber a constituir-se como ferramenta para a atividade docente: a matemática para ensinar. Trata-se de uma matemática que o professor precisa mobilizar para ensinar o objeto da docência. Tais matemáticas são elaboradas no contexto das relações que se estabelecem, num dado tempo histórico, entre os diferentes campos mencionados anteriormente, qual sejam: a docência, o campo disciplinar matemático, o campo da Educação Matemática e as ciências da educação.

Assim, nos parece importante caracterizar as relações entre formação e ensino do ponto de vista da centralidade do saber produzido no âmbito dessas relações. A esse saber denominamos matemática do ensino. A matemática do ensino revela em cada época as articulações estabelecidas entre a matemática a ensinar e a matemática para ensinar.

\section{Considerações finais}

Retornemos ao objetivo deste estudo, a partir da questão norteadora que tem movido as pesquisas realizadas por meio de projeto coletivo amplo de investigação envolvendo o saber profissional do professor que ensina matemática: Que processos e dinâmicas estão presentes nas mudanças que ocorrem relativamente à matemática considerada como um saber profissional do professor que ensina matemática? O retorno à questão aqui, não tem como fim dar-lhe resposta, mas intenta atingir o objetivo deste artigo: concluir que tal interrogação de pesquisa poderá 
constituir-se em problemática original para a Educação Matemática, contribuindo para a sua consolidação como campo disciplinar.

O tratamento da matemática como saber profissional da docência é tema não abordado pelo campo disciplinar matemático. Para este campo a matemática é única, apenas quando levada à escola deverá apresentar-se em seus elementos. Trata-se assim de uma diferença de nível: elementar e superior. Para o campo disciplinar matemático não tem sentido mencionar-se a existência de várias matemáticas. Ao que parece tem-se a lógica de que o professor formado na matemática avançada terá pleno domínio da matemática elementar, do ponto de vista de seus conteúdos de ensino. Esse posicionamento parece estar enraizado desde tempos iniciais do nascimento das faculdades de filosofia no Brasil. Em particular, da criação da seção de Matemática da Universidade de São Paulo, fundada em 1934. Emblemáticas foram as afirmações de um seus fundadores - o matemático Luigi Fantappiè - no ensino de seu discípulo Benedito Castrucci, matemático, geômetra que se tornou referência importante em tempos do chamado Movimento da Matemática Moderna:

Segundo o depoimento de Castrucci, ele não fez esse ano de estudos [das matérias pedagógicas] porque assim Ihe sugeriu Fantappiè: "estuda Matemática, deixa de lado essas coisas de didática, porque didática só tem uma regra boa: saber a matéria, se você souber a matéria, o resto você é um artista e se for um mau artista será a vida toda, se for um bom artista será um bom professor. 0 resto põe tudo de lado" (SILVA, 2000, p. 13).

Assim, como o campo disciplinar matemático não formula interrogações sobre a matemática a estar presente na formação de professores e no ensino, considerando-se como autossuficiente para definição desses saberes, tampouco o saber profissional do professor de matemática tem sido posto como temática de pesquisa no âmbito das ciências da educação. 0 campo educacional, as ciências da educação, como já afirmaram Ramos \& Silva (2014), não têm interesse em tratar de especificidades disciplinares, ocupando-se de questões amplas da educação.

Não tratada pelo campo disciplinar matemático e ignorada pelas ciências da educação, a matemática como saber profissional poderá ser tema de análise dos diálogos e embates que esses campos travam entre si relativamente à produção de novos saberes para o ensino e para a docência. Neste caso, a afirmação de que a Educação Matemática se constitui como campo interdisciplinar, deixa de ser um expediente puramente retórico utilizado para minimizar tensões entre diferentes campos disciplinares e da docência. A análise da produção de saberes, da produção da matemática do ensino, ensejando estudos sobre os embates dos diferentes campos, 
coloca a Educação Matemática como seara interdisciplinar não por estabelecer relações de solidariedade e proximidade entre diferentes espaços de produção científica, mas por confronto, por disputas pela hegemonia da autoridade de expressar cientificamente como se dá a produção de saberes a serem mobilizados na formação de professores e no ensino de matemática. Como resultado dessa empreitada, a Educação Matemática poderá redirecionar estudos futuros, vendo como sua a original interrogação de pesquisa: Que processos e dinâmicas estão presentes nas mudanças que ocorrem relativamente à matemática considerada como um saber profissional do professor que ensina matemática?

\section{Referências}

BERTINI, Luciane de Fatima; MORAIS, Rosilda dos Santos; VALENTE, Wagner Rodrigues. A matemática a ensinar e a matemática para ensinar: novos estudos sobre a formação de professores. São Paulo: Livraria da Física, 2017.

BOURDIEU, Pierre. Science de la Science et réflexivité. Paris: Raisons D’Agir Éditions, 2001.

CHERVEL, André. História das disciplinas escolares: reflexões sobre um campo de pesquisa. Teoria \& Educação, São Paulo, n. 2, p. 177-231, 1990.

CIEM. Rapport préliminaire sur l'organisation de la Commission et le plan general de ses travaux. In: L'Enseignement mathématique. Paris/Genève. v. 10, 1908.

FIORENTINI, Dario; PASSOS, Cármen Lúcia Brancaglion; LIMA, Rosana Catarina Rodrigues (Orgs.). Mapeamento da pesquisa acadêmica brasileira sobre o professor que ensina matemática: período 2001-2012. Campinas: FE/UNICAMP, 2016.

FIORENTINI, Dario et al. Estudos do estado da arte da pesquisa sobre o professor que ensina matemática. Dossiê Temático. Zetetiké, Campinas, v. 25, n. 1, p. 1-6, 2017.

HÉBRARD, Jean. A escolarização dos saberes elementares na época moderna. Teoria \& Educação, São Paulo, n. 2, p. 65-110, 1990.

HOFSTETTER, Rita; SCHNEUWLY, Bernard. Saberes: um tema central para as profissões do ensino e da formação. In: VALENTE, Wagner Rodrigues.; HOFSTETTER, Rita (Orgs.). Saberes em (trans)formação: tema central da formação de professores. São Paulo: Livraria da Física, 2017. p. 113-172.

HOFSTETTER, Rita; SCHNEUWLY, Bernard. "Profissionalização" e formação de professores: uma tipologia dos saberes de referência para a docência. In: VALENTE, Wagner Rodrigues (Org.). Ciências da Educação, Campos Disciplinares e Profissionalização: Saberes em Debate para a Formação de Professores. São Paulo: Livraria da Física, 2020.

JULIA, Dominique. A cultura escolar como objeto histórico. Revista Brasileira de História da Educação, Campinas, n. 1, p. 9-43, jan./jun. 2001. 
KLEIN, Félix. Matemática elementar de um ponto de vista superior. Volume I - Parte I Aritmética. Lisboa: Sociedade Portuguesa de Matemática, 2009 [1908].

LIMA, Elon Lages. Matemática e Ensino. Lisboa: Gradiva, 2004.

RAMOS, C. R.; SILVA, J. A. A emergência da área de ensino de ciências e matemática da Capes enquanto comunidade científica: um estudo documental. Investigações em Ensino de Ciências, Porto Alegre, v. 19, n. 2, p. 363-380, 2014.

SILVA, Circe Mary Silva A Faculdade de Filosofia, Ciências e Letras da USP e a formação de professores de matemática. Anais da 23a. Reunião Anual da ANPEd. 24 a 28 de setembro de 2000. Disponível em: http://23reuniao.anped.org.br/textos/1925p_poster.PDF. Acesso em: 15 abril. 2021.

VINCENT, Guy.; LAHIRE, Bernard; THIN, Daniel. Sobre a história e a teoria da forma escolar. Educação em Revista, Belo Horizonte, n. 33, p. 7-47, jun. 2001. 